2016 Modular and Offsite Construction (MOC) Summit

Edmonton, Alberta, Canada, September 29 - October 01, 2016

(1)

\title{
Advancing Formwork Systems for the Production of Precast Concrete Building Elements: from Manual to Robotic
}

\author{
Mi PAN ${ }^{1 *}$ and Wei PAN ${ }^{1}$ \\ ${ }^{1}$ Department of Civil Engineering, The University of Hong Kong \\ "Corresponding author's e-mail: panmi@connect.hku.hk
}

\begin{abstract}
The utilization of precast concrete offers significant benefits in terms of increased material efficiency, safety, labor productivity, and reduced time, cost and wastage over conventional onsite construction. In the meantime, challenges exist in the precast concrete production in the high requirements for dimensional accuracy of precast elements, flexibility and reusability of formwork, and stability of shuttering. Formwork systems are a critical component of the precast production line, which is also the key to innovation from manual to automated and robotic. Previous studies seldom examined the competitive features of such systems within the context of the building prefabrication process. The aim of this paper is to explore the future development directions of, and to identify transferable advanced technologies for, advanced formwork systems in the production of precast concrete building elements. The research was carried out by comparing the conventional and advanced approaches drawing on the case of high-rise buildings in Hong Kong. The results indicate that automation and robotic technologies offer unique advantages in the betterment of the formwork system. Besides gains in productivity, reliability and accuracy, the adoption of robotic systems also provide the great benefit of cost-effectiveness owing to the high labor cost and fast growing market in Hong Kong. However, there also exist barriers to advancing formwork systems for precast, including industry and culture reluctance, high capital costs and skill shortages. The findings should contribute to a better understanding of how automated and robotic technologies could advance the formwork systems in the precast production, which can further reap the benefits of prefabrication and facilitate innovation in building industry.
\end{abstract}

\section{KEYWORDS}

Precast concrete; Formwork system; Construction automation and robotics; Prefabrication

\section{INTRODUCTION}

Prefabrication can be generally described as the manufacturing of building components and systems in an off-site factory prior to on-site assembly. Whether the building materials are timber, steel, masonry or concrete, the benefits of prefabrication have been widely recognized and extensively discussed, which include and are not limited to increased material efficiency, safety, labor productivity, workmanship and reduced time, cost and wastage (Pan et al., 2012). Meanwhile, this approach has the potential to revolutionise the construction industry from labor-intensive to technology-intensive, by offering the platform which mechanized, automated and robotic 
technologies can easily trespass (Neelamkavil, 2009). Automation and robotics is capable to reap greater benefits of off-site construction in terms of automated design and optimization of resource utilization, sensor-based material control and monitoring, automated production line, CAD factory layout plan, etc. (Bock and Linner, 2015; Neelamkavil, 2009).

Concrete is the most pervasively used building material in the world (Bock and Linner, 2015). Precast concrete have been widely adopted in buildings components including walls, floors, roofs, stairs, columns, and beams, etc. (Elematic, 2016). Automation and robotics has found its way in precast concrete production from design, scheduling, manufacturing to delivery, while the dominant way in the real-world practice is still in labor-intensive and low mechanization level. Despite the fruitful advantages explored in the up-take of off-site production technologies (Pan et al., 2012; Tam et al., 2007), there is still a lack of works digging into the further improvement opportunities offered by the emerging automation and robotics, with clear guidance on technical routes and strategic integration. Thus, there is a need to look at the critical part that is well-suited to ignite innovation from manual to robotic. The formwork system is therefore considered as the core part in the precasting plant where the appearance of the concrete is shaped in the mould with supporting structures until attaining adequate resistance, decisive for the quality and accuracy of the precast elements, flexibility and productivity of the production (Vähä et al., 2013; Weckenmann, 2016a). The aim of this paper is to discover how robotics can be implanted into the formwork system to foster innovation. The paper first provides a structured review of formwork systems applied in the precast concrete production to demonstrate the technical feasibility for formwork innovation. It then explores the potential opportunities and challenges along with the advancement of the formwork systems drawing on the practical case of precast high-rise buildings in Hong Kong.

\section{METHODS}

This study is conducted through two stages. The first stage is based on a review of formwork systems in precast concrete production to identify the routes for betterment from manual to robotic. Formwork systems are focused on as they are a critical part of the production of precast concrete building elements. Data collection for an all-sided review is carried out from a widespread range of sources, including literature, industry report, company website and leaflets, videos and site visits. The second stage involves Hong Kong as a case study to bolster the exploration from a more practical perspective. Case study has been frequently applied in the field of construction engineering and management as an exploratory method (Taylor et al., 2011). Hong Kong has a well-developed building construction industry experienced in prefabrication, but the level of automation in factory is still low (Jaillon and Colleen 2009). Facing the increasing labor cost and fast growing market in Hong Kong, it is essential to study advanced technology to further enhance the efficiency and lower the production cost. To facilitate a better understanding of practical value of manual to robotic transition, comparative analysis is executed between the traditional and robotic approaches.

\section{FORMWORK SYSTEMS IN PRECAST CONCRETE PRODUCTION}

According to relevant literature and guidance [e.g., Building Department (BD), 2016; Elematic, 2016; The Hong Kong Institution of Engineers (HKIE), 2015; Jha, 2012], the basic production processes of precast concrete elements on formwork system can be outlined as in Figure 1, including preparation works, mould or formwork arrangement, reinforcement and fixing setting, 
concrete casting, curing, and demoulding. Formwork preparation, mould arrangement and demoulding are thereinto the primary operating steps relating formwork system to support the repetitive production of flat and constructive precast concrete elements (Weckenmann, 2016a). Processes are slightly different for manufacturing different types of elements, for example, nonload bearing, non-reinforced wall panels do not need reinforcement setting.

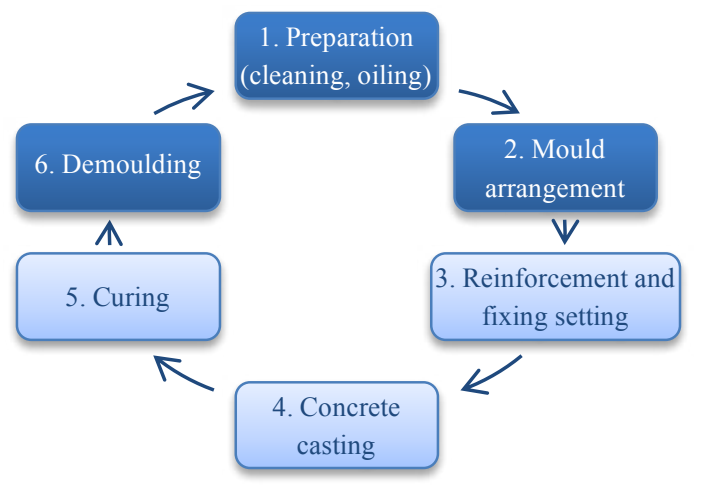

Figure 1. Basic production process of precast concrete elements

\section{Types of formwork systems}

Formwork systems is the critical component in precast concrete production plants where concrete elements are shaped and cured. Poor formwork can affect the quality of elements, causing even deflection or leaky problems when assembled on site. Each formwork option needs to be tailored to the specific requirements, including product forms, production capacity, land areas, personnel, and investment. But in general, they can be categorized in terms of the material of moulds, applicable products, or the ways of production (Jha, 2012). As for production mode, formwork systems can be broadly grouped into stationary and mobile, or horizontal, vertical and volumetric.

Stationary and mobile. Formwork systems can be classified as stationary or mobile, according to the mould position in casting (Jha, 2012). Stationary formwork systems are static that enable precast concrete elements to be produced in one place for both moulding and demoulding, while mobile formwork systems have movable moulds to be transported from one work station to another in a carousel production line. Stationary production is the traditional approach, through which different types of elements can be manufactured on exclusive formworks in one production hall. The stationary systems are often with moulds produced beforehand and fixed during the repetitive use, some may be hydraulically adjustable. The setup is quick with minimal shuttering works. In contrast, carousel plant is initiated by the idea of circular production to further enhance production capacity, well suited for laminary elements.

Horizontal, vertical and volumetric. Directional speaking, concrete elements can be precasted in horizontal, vertical or even volume mould, resting with element surface finish requirements and spatial conditions. Horizontal formwork systems fit for both laminary and constructional elements, requiring large areas for production and storage. It is more prevalently adopted as applicable to different types of precast elements. Whereas the vertical ones apply to solid slabs, with the mould compartments grouped to enable simultaneously production of several concrete panels, taking up very little space, which also termed as battery moulds (Elematic, 2016; Jha, 2012). The advantages have been widely proved in terms of convenient use, satisfied quality, high efficient, and small footprint (Weckenmann, 2015). Volumetric moulds are used for three-dimensional precast 
concrete components in favour of minimal dimensional tolerances and less on-site assembly works, but the flexibility of formworks is limited and the end-products face bottlenecks in transportation.

\section{Advancing formwork systems to robotic}

To enable robotic operation of formworks, most attempts have been made on the production of facade elements, which have the extensive demand in buildings and standard structures (Elematic, 2016; Weckenmann, 2015). Specifically, the rapid development of machinery has witnessed the conventional tailor-made fixed moulds to be replaced by a range of shuttering profiles, which are flexibly assembled and placed on casting pallets in circular production systems, and applicable for facade elements in different size, thickness as well as door and window openings. The advanced production system also allow flexible level of automation to be imported.

Several pioneering companies for precast concrete production, like Elematic, Weckenmann, and Vollert, have offered a variety of solutions of plant, equipped with formwork systems from manual to robotic operated. Switchable magnets are integrated in shuttering profiles to quickly and stably fasten the profiles on pallets, and make them easily-handled and robot-compatible. Shuttering robot, or formwork robot (Figure 2) are thereby developed for efficiently and precisely positioning shuttering profiles, and also capable of plotting, demoulding and oiling. Based on CAD-data and magnetic system, the shuttering robot can automatically place required shuttering profiles from storage on casting pallets in an efficient, elastic, mistake-free manner. The robot can later on deshutter the profiles back to the storage after curing. The benefits of robotic formwork system are well reported by the pioneers in industry and academia, summarized as (1) Production capacity can be vastly improved by fast shuttering, deshuttering and executing of other affiliated tasks combined with a smooth and consecutive production line; (2) Higher quality and greater accuracy of products can be reaped, and thus guaranteeing the elements to be well-fitted into the in-situ assembly; (3) Labor costs can be minimized since the number of skilled workman is drastically reduced; and (4) Workplace safety can be improved as hazardous and arduous works are almost avoided.

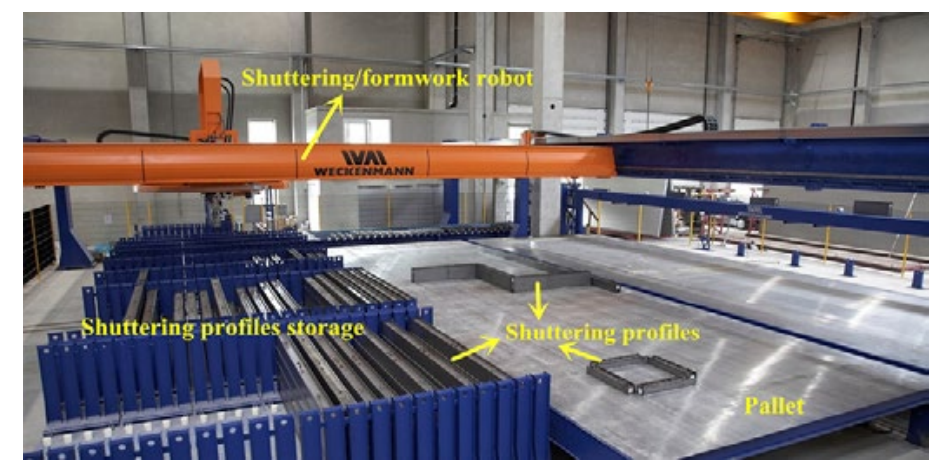

Figure 2. Robotic formwork system with shuttering robot (based on Weckenmann, 2016b)

Apart from horizontal production, the use of robotics in vertical and volumetric formworks are relatively limited. Given the state-of-the-art practice within the context of automated and robotic technology, some possible future directions can be identified. For example, the transportable site factory based on battery moulds has been developed and successfully operated in Singapore, contributing to a dramatic reduction in environmental impacts from transportation and in land space requirement (Weckenmann, 2015). Such practice is attractive under the increasingly 
emphasis on sustainability. The on-site factory has fixed formworks with only opening and closing status during production process, and application of robotics is still untapped. A further innovation by robotics can be explored in terms of accessory tasks, innovate to flexible production, etc.

\section{OPPORTUNITEIS AND CHANLLENGES: THE CASE IN HONG KONG Precast concrete practice and formwork systems applied in Hong Kong}

Hong Kong has over 50 years' experience in precast high-rise buildings (Jaillon and Colleen 2009). The usage of precast concrete ranges from elements like facades, slabs, to volumetric bathroom and kitchen (Jaillon and Colleen 2009). Since 1990s, precast concrete components have been prevalently utilized in public buildings for better workmanship, quality and efficiency, and became a mandatory in 1997 [Housing Authority (HA), 2015]. But the practice in private buildings was still low. In 2001, the government has implemented incentives schemes with Gross Floor Area (GFA) exemption granted for building projects using prefabricated components for the sustainability sake (Jaillon and Colleen 2009). Such incentives result in considerable cost benefits to developers in the private sector, deemed as the major driver to promote precast adoption in the private buildings (Jaillon and Colleen 2009). Due to the expensive land and labor cost in Hong Kong, precast concrete factories have been generally set up in mainland China (Wong et al., 2003).

As for formwork systems, fixed tailor-made moulds are dominant in precast concrete production taken up by Hong Kong construction companies (HA, 2015; HKIE, 2015). A lead time is needed to manufacturing the moulds, based on the production plan of the precast elements $(\mathrm{BD}, 2016$; HKIE, 2015). Although labor requirement on site has been reduced, manual works still largely needed in prefabrication yard due to the low level of automation. Therefore, additional period for mould fabrication and cost of off-site manpower and transportation inhibit the capability of prefabrication to a low-cost and high-efficiency building construction in Hong Kong. Combined with the high capital cost of prefabrication practice, even with the GFA exemption incentives, the rate of return is limited and the uptake is low for small and medium companies in private sector. Hence, it is a necessity to polish up the current lag-behind formwork system in Hong Kong.

\section{Comparative analysis of traditional and robotic formwork systems in Hong Kong}

In order to amplify the benefits and further unleash the potential of precast concrete adoption in Hong Kong, the advancement of the formwork systems plays an important role. A comparative study is carried out to examine the differentiated performance in precast concrete production upon traditional Hong Kong practice and robotic horizontal formwork systems, in the aspects of three key performance indicators in project management - cost, time, and quality (Table 1).

Table 1. Comparative analysis of traditional and robotic formwork systems for Hong Kong

\begin{tabular}{|c|c|c|}
\hline & Traditional formwork systems & Robotic forr \\
\hline \multirow[t]{4}{*}{ Cost } & - $\quad$ Tailor-made production cost & - High \\
\hline & High & - $\mathrm{Hi}$ \\
\hline & factory & \\
\hline & & - Reduced land cost for the factory \\
\hline Time & $\begin{array}{l}\text { - Additional production time in each } \\
\text { project } \\
\text { - Possible additional manual reworking } \\
\text { time }\end{array}$ & 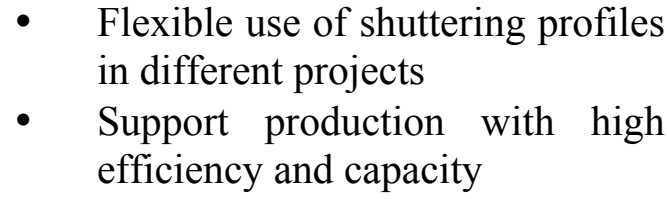 \\
\hline
\end{tabular}




\begin{tabular}{|c|c|c|}
\hline Quality & - Unguaranteed precision & $\begin{array}{ll}\text { - } & \text { Avoid manual reworking time } \\
\text { - } & \text { High precision } \\
\text { - } & \text { Tight tolerance }\end{array}$ \\
\hline
\end{tabular}

Reference: BD, 2016; Elematic, 2016; HA, 2015; HKIE, 2015; Weckenmann, 2016a,2016b; Wong et al., 2003

Cost. Robotic formwork systems come with high capital costs and maintenance cost, but return with a high economic value in long term. Labor costs can be substantially reduced by the use of robotics. The flexible use of shuttering profiles controlled by robotic system also results in the elimination of moulds making costs each time. Robotic formworks support the circulation production and cut down the site area (Elematic, 2016). Given the high labor wage and land charge in Hong Kong, the cost competitiveness of robotic formwork systems can be well embodied.

Time. Current practice in Hong Kong requires normally 1.5 to 6 months lead time to produce moulds based on the production plan of the precast elements (HKIE, 2015). Generally in Hong Kong, the production cycle for a non-complicated precast element is one day (HKIE, 2015). Then, according to precast requirement and planned working cycle per story, the number of moulds to manufactured can be estimated (HKIE, 2015). Howbeit robotic formwork system with flexible shuttering profiles does not need additional moulds manufacturing time. Although flexible robotic formwork systems need setup time, this can be ignored since the setting time per formwork profile is only around 30 seconds by robots (Weckenmann, 2016b). Besides, the robotic formworks support a high efficient and capacity production (Elematic, 2016). Robotic systems also provide high accuracy and avoid manual reworking time.

Quality. The quality of the precast products largely dependent on the precision of formwork. Hong Kong did face several quality issues related to precast concrete, including leaky, joining problems (Wong et al., 2003). The robotic formwork system with precise control can help to achieve a high degree of dimensional accuracy of the precast concrete elements, and tight tolerances for quick, guaranteed assembly on the building sites (Weckenmann, 2016a).

\section{Opportunities and Challenges}

The paper manifests that the advanced formwork system is a profitable investment for precast high-rise buildings in Hong Kong, far superior to the current mould systems in respects of cost, time and quality. The relevant opportunities are further explored as follows.

- Prefabrication is generally unappealing to private building projects in Hong Kong because of the unsatisfied return on investment. The advanced robotic formwork should contribute to a clear vision of how prefabrication can result in an attractive economic return, and facilitate the take-up in private sector.

- The free market economy in Hong Kong was driving capitalists to move the prefabrication factories to the mainland China many years ago, to save cost in labor and land (Wong et al., 2003). However, the economic rewards are limited now as ever-increasing labor and land expense in mainland, as well as the additional costs in long transpiration. Hence, robotic formworks offer a terrific opportunity for Hong Kong to bring back the production business with setting up smart, little labor required, and small land occupied precast yard.

- Human to machine collaboration is always considered the big key for technological innovation (Sheridan, 2002), and Hong Kong has encountered difficulties from worker 
reluctance for innovations in construction industry. The robotic formwork system offers the opportunity for Hong Kong construction industry to look into the mechanisms in maintaining a harmonious human-machine collaboration, and to well handle future innovations.

- The experience of Singapore on advanced mobile battery mould also offer another feasible and worthwhile solution for Hong Kong, especially for building projects in the densely urban area. This is worthwhile to explore in future.

Nevertheless, there also exist barriers and challenges. According to the identified barriers to prefabrication and other innovation adoption in Hong Kong (HA, 2015; Jaillon and Colleen 2009), potential concerns about advancing formwork systems are as follow.

- Industry and culture reluctance may engender. Since the current production is mainly conducted in mainland, the impact for local labor marker as well as the resistance could be limited. Therefore, the reliability, safety, and convenience of the system should be well demonstrated to minimize the potential reluctance.

- High capital costs of the robotic system can curb the small and median companies to adopt, while large companies may also hesitate. A collaborative yard with shared benefits and risks by several companies might be a solution in the first place.

- Another challenge is the skill shortages and limited experience of such innovative system in Hong Kong. A favorable environment should be created for the better transfer of the knowledge, with government and institutional support.

\section{CONCLUSIONS}

This paper has provided a literature review of multifarious formwork systems for precast concrete production in general, with the focus on how robotic technology leads to breakthroughs. The work has identified that previous attempts were primarily made on the production of facade elements in a horizontal way. It has further demonstrated that robotic technologies offer unique advantages in the betterment of the formwork system in the matter of improved productivity, reliability, accuracy, safety and reduced labor demand and costs. From the review of the knowledge and practices worldwide, this paper also suggests a future possible direction for robotic importation in mobile battery moulds. Hong Kong as a particular case study has been conducted to bolster the work from a more practical perspective. Compared to the current mould system applied in Hong Kong, robotic formwork system can reap prolific benefits in terms of cost, time and quality. Advancing the formwork to robotic also offer great opportunities for the market to grow and reform. To facilitate the technology transfer, potential challenges in reluctance, high capital costs, skill shortages should be well managed. The findings should contribute to a better understanding of how automated and robotic technologies could be applied to improve formwork systems in the off-site prefabrication, considering increasingly complicated and pluralistic buildings, and what are the reaped benefits. Future research should examine the holistic feasibility of robotic solutions with detailed case studies and quantitative analysis, and explore the strategic deployment under different scenarios.

\section{ACKNOWLEDGEMENTS}

The research was supported by a grant from the Germany / Hong Kong Joint Research Scheme sponsored by the Research Grants Council of Hong Kong and the German Academic Exchange Service (Reference No. G-HKU704/15). We would also like to thank Prof Thomas Bock and Dr Thomas Linner of Technical University of Munich for organizing factory visits in Germany. 


\section{REFERENCES}

Building Department (BD). (2016). Code of Practice for Precast Concrete Construction 2016. BD. Hong Kong.

Bock, T., and Linner, T. (2015). Robotic Industrialization: Automation and Robotic Technologies for customized Component, Module and Building Prefabrication, Cambridge University Press, Cambridge.

Elematic. (2016). "Precast wall production: SEMI-PRO-EDGE." <http://elematic.studio.crasman. fi/pub/Marketing/Brochures/Wall+brochure/Elematic_Wall_brochure_2016_EN_web.pdf> (June 10, 2016).

Housing Authority (HA). (2015). Quality Control and Supervision of Off-site Manufactured Precast Concrete Components for Use in Housing Authority's Public Housing Developments. HA. Hong Kong.

Jaillon, L., and Colleen S. P. (2009). "The evolution of prefabricated residential building systems in Hong Kong: A review of the public and the private sector." Automation in Construction, 18(3): 239-248.

Jha, K. N. (2012). "Formwork for Concrete Structures." McGraw Hill Education.

Neelamkavil, J. (2009). Automation in the prefab and modular construction industry. 26th Symposium on Construction Robotics ISARC.

Pan, W., Gibb, A. G., and Dainty, A. R. (2012). "Strategies for integrating the use of off-site production technologies in house building." Journal of Construction Engineering and Management, 138(11), 1331-1340.

Sheridan, T. B. (2002). "Humans and automation: System design and research issues." John Wiley \& Sons, Inc. New York, NY, USA

Tam, V. W., Tam, C. M., Zeng, S., and Ng, W. C. (2007). "Towards adoption of prefabrication in construction." Building and environment, 42(10), 3642-3654.

Taylor, J. E., Dossick, C. S., and Garvin, M. (2011). "Meeting the burden of proof with case-study research.” J. Constr. Eng. Manage., 137(4), 303-311.

The Hong Kong Institution of Engineers (HKIE). (2015) Precast concrete construction handbookAn explanatory handbook to Code of Practice for Precast Concrete Construction 2003. HKIE. Hong Kong.

Vähä, P., Heikkilä, T., Kilpeläinen, P., Järviluoma, M., and Gambao, E. (2013). "Extending automation of building construction - Survey on potential sensor technologies and robotic applications." Automation in Construction, 36, 168-178.

Weckenmann. (2015). "The Mobile Battery Mould (MBM) for the production of precast concrete elements in immediate vicinity of the construction site" <http://www. weckenmann.com/en/topics-and-technology/mobile-battery-mould-(mbm)> (May 15, 2016)

Weckenmann. (2016a). "Formwork specialist for stationary production and circulation plants." Concrete Plant International 3. <http://www.weckenmann.com/media/430276/1603 _weckenmann_en.pdf $>$ (May 15, 2016)

Weckenmann. (2016b). Formwork robots. <http://www.weckenmann.com/en/equipment-and-for mwork/equipment-and-components/formwork-robots/> (May 20, 2016)

Wong, R., Hao, J. L., and Ho, C. M. (2003). Prefabricated building construction systems adopted in Hong Kong. In Proc. of the International Association for Housing Science on Word Congress of Housing: Process and Product, Montreal, Canada. 